\title{
FREQUENCY OF ANEMIA AMONG WOMEN PRESENTING WITH SHORT INTER-PREGNANCY INTERVAL AT A TERTIARY CARE HOSPITAL.
}

\author{
DR. MARVA MASOOD, MBBS \\ NISHTAR HOSPITAL, MULTAN, PAKISTAN. \\ DR. NOREEN NAZAR, MBBS \\ NISHTAR HOSPITAL, MULTAN, PAKISTAN. \\ DR. MUHAMMAD ABDULLAH KHAN, MBBS \\ PAKISTAN INSTITUTE OF MEDICAL SCIENCES, ISLAMABAD.
}

\begin{abstract}
;
Background; The time interval between pregnancies is considered to be an important and modifiable risk factor in terms of adverse perinatal outcomes. This study was done to determine the frequency of anemia in pregnant women having short interpregnancy interval. Materials and methods; All the pregnant women with short interpregnancy interval were registered from Department of Gynecology and Obstetrics, Nishtar Hospital Multan, Pakistan. Examination was done including general physical examination. Those with interpregnancy interval less than 6 months were included in study. Detailed history was taken regarding parity, duration of pregnancy. Duration of gestation was estimated according to patients last menstrual period. Three $\mathrm{ml}$ venous blood sample was drawn and sent to the pathology laboratory of Nishtar Hospital Multan for Hb levels analysis. Data was entered and analyzed by SPSS version 20. Results; Mean age of our study cases was noted to be $27.83 \pm 4.95$ years (with minimum age of our study cases was 21 years while maximum age was noted to be 38 years). Of these 90 study cases, $51(56.7 \%)$ were from rural areas, $73(81.1 \%)$ were normal weight 11(12.2\%) were overweight and $6(6.7 \%)$ were obese. Seventy eight $(86.7 \%)$ were illiterate. Of these 90 study cases, $73(81.1 \%)$ were having poor socioeconomic status, $11(12.2 \%)$ were diabetic and $17(18.9 \%)$ were hypertensive. Mean body mass index (BMI) of our study cases was noted to be $22.31 \pm 2.07 \mathrm{Kg} / \mathrm{m}^{2}$. Mean gestational age of our study cases was noted to be $24.02 \pm 8.31$ weeks. Mean $\mathrm{Hb}$ level was noted to $10.67 \pm 0.893 \mathrm{~g} / \mathrm{dl}$ (with minimum $\mathrm{Hb}$ level was $9.6 \mathrm{~g} / \mathrm{dl}$ while maximum $\mathrm{Hb}$ level was $12.5 \mathrm{~g} / \mathrm{dl}$ ). Mean interpregnancy interval was $4.23 \pm 0.98$ months (with minimum interpregnancy interval was 2.5 months while maximum interpregnancy interval was 6 months). Anemia was noted in $74(82.2 \%)$ our study cases and only $23(25.6 \%)$ of our study cases were taking iron supplements. Conclusion; Short interpregnancy interval less than 6 months is related with adverse pregnancy outcomes. Very high frequency of anemia was noted in our study cases having interpregnancy interval less than 6 months. Anemia was significantly associated with residential status, hypertension and iron supplementation. Birth spacing is an issue which women should have some control over. Educational interventions, including birth control, should be applied during prenatal visits and following delivery.
\end{abstract}

Keywords; Short interpregnancy Interval, anemia, hemoglobin.

DOI: $10.7176 / \mathrm{JMPB} / 67-05$

Publication date:August $31^{\text {st }} 2020$

\section{Introduction:}

Anemia, defined as a decreased concentration of blood hemoglobin, is one of the most common nutritional deficiency diseases observed globally and affects more than a quarter of the world's population ${ }^{1}$. It is a major public health problem affecting all ages of the population with its highest prevalence among children under five years of age and pregnant women ${ }^{1,2}$. Globally, anemia affects 1.62 billion people (25\%), among which 56 million are pregnant women ${ }^{3}$. Anemia in pregnancy is a major cause of morbidity and mortality of pregnant women in developing countries and has both maternal and fetal consequences. It is estimated that anemia causes more than 115,000 maternal and 591,000 perinatal deaths globally per year ${ }^{4,5}$. The time interval between pregnancies is viewed as an important and modifiable risk factor for adverse birth outcomes ${ }^{6}$. It offers a great potential in protecting the health status of the mothers, and improving outcome of subsequent pregnancy ${ }^{7}$. This remains to be a major challenge among women in developing countries associated with increased risk for maternal and neonatal mortality. Traditionally women with a short inter-pregnancy interval will not have sufficient time to recover and get ready for the subsequent pregnancy. This includes socio-economic, cultural, psychological and physical body preparedness. Interpregnancy intervals less than 18 months and greater than 59 months are significantly associated with an increased risk of adverse perinatal outcomes. ${ }^{8,9}$ The biological mechanism between short interpregnancy 
interval (IPI) and poor maternal and neonatal outcomes is hypothesized to be due to insufficient time for the mother to recover from the nutritional burden and stress of the previous pregnancy. Specifically, depleted maternal protein, low energy status, and deficiencies in folate and iron have been considered ${ }^{10}$. The impact of short IPI is greater in very young women; this is because an immature adolescent who is still growing, may compete with the fetus for nutrients. Pregnant women with short interval have increased risk of uterine rupture or scar dehiscence, failure trial of scar, placenta abruption, placenta previa, antenatal and perinatal infections ${ }^{11}$. Optimal spacing between pregnancies has greater health advantages for both mother and child, which can give an opportunity for the mother to recover from pregnancy, labor and lactation. Longer time period between births allows the next pregnancy and birth to occur more likely to be at full gestation and growth. Studies also revealed optimum birth interval can improve the health status of children. Survival of children could increase each year if all women had optimal birth interval and decrease child mortality ${ }^{12,13}$. Lilungulu et al ${ }^{7}$ reported anemia in $94 \%$ pregnant ladies with short interpregnancy interval.

\section{Materials and methods}

All the pregnant women with short inter-pregnancy interval were registered from Department of Gynecology and Obstetrics, Nishtar Hospital Multan, Pakistan. Primigravida, multiple gestations, Patients with known diseases like diabetes and hypertension and patients with previous history of miscarriage / preterm birth were excluded from our study. Examination was done including general physical examination. Those with interpregnancy interval less than 6 months were included in study. Detailed history was taken regarding parity, duration of pregnancy. Duration of gestation was estimated according to patients last menstrual period. Three ml venous blood sample was drawn and sent to the pathology laboratory of Nishtar Hospital Multan for Hb levels analysis. Data was entered and analyzed by SPSS version 20 .

\section{Results;}

Our study comprised of a total of 90 pregnant ladies having short inter-pregnancy interval meeting inclusion criteria of our study. Mean age of our study cases was noted to be $27.83 \pm 4.95$ years (with minimum age of our study cases was 21 years while maximum age was noted to be 38 years). our study results have indicated that majority of our study cases i.e. $62(68.9 \%)$ were aged $20-30$ years of age. Of these 90 study cases, $51(56.7 \%)$ were from rural areas, $73(81.1 \%)$ were normal weight $11(12.2 \%)$ were overweight and $6(6.7 \%)$ were obese. Seventy eight (86.7\%) were illiterate. Of these 73 study cases, $73(81.1 \%)$ were having poor socioeconomic status, $11(12.2 \%)$ were diabetic and $17(18.9 \%)$ were hypertensive. Mean body mass index (BMI) of our study cases was noted to be $22.31 \pm 2.07 \mathrm{Kg} / \mathrm{m}^{2}$ (with minimum BMI was $19.2 \mathrm{~kg} / \mathrm{m}^{2}$ while maximum BMI was $31.3 \mathrm{~kg} / \mathrm{m}^{2}$ ). Mean gestational age of our study cases was noted to be $24.02 \pm 8.31$ weeks (with minimum gestational age was 11 weeks while maximum gestational age was 34 weeks). Mean interpregnancy interval was $4.23 \pm 0.98$ months (with minimum interpregnancy interval was 2.5 months while maximum interpregnancy interval was 6 months). Mean $\mathrm{Hb}$ level was noted to $10.67 \pm 0.893 \mathrm{~g} / \mathrm{dl}$ (with minimum $\mathrm{Hb}$ level was $9.6 \mathrm{~g} / \mathrm{dl}$ while maximum $\mathrm{Hb}$ level was 12.5 $\mathrm{g} / \mathrm{dl})$. Anemia was noted in $74(82.2 \%)$ our study cases and only $23(25.6 \%)$ of our study cases were taking iron supplements

\section{Discussion;}

The time interval between pregnancies is considered to be an important and modifiable risk factor in terms of adverse perinatal outcomes ${ }^{14-15}$. Our study comprised of a total of 90 pregnant ladies having short inter-pregnancy interval meeting inclusion criteria of our study. Mean age of our study cases was noted to be $27.83 \pm 4.95$ years (with minimum age of our study cases was 21 years while maximum age was noted to be 38 years). Our study results have indicated that majority of our study cases i.e. $62(68.9 \%)$ were aged $20-30$ years of age. A study conducted by Al - Jasmi Fatima et al ${ }^{16}$ in UAE women reported maternal age $27.6 \pm 4.9$ years. These results are similar to that of our study results. Howard et al ${ }^{10}$ reported similar findings in women with short interpregnancy interval. Lilungulu et $\mathrm{al}^{7}$ reported anemia in $23.4 \pm 1.7$ years mean age of pregnant ladies with short interpregnancy interval which is in compliance with that of our study results. Hussaini et al ${ }^{17}$ reported similar findings.

Of these 90 study cases, $51(56.7 \%)$ were from rural areas, $73(81.1 \%)$ were normal weight $11(12.2 \%)$ were overweight and $6(6.7 \%)$ were obese. Seventy eight $(86.7 \%)$ were illiterate. Poor educational status was also reported by Lilungulu et al ${ }^{7}$ with $99.1 \%$ having up to primary level of education.

Of these 73 study cases, $73(81.1 \%)$ were having poor socioeconomic status, $11(12.2 \%)$ were diabetic and 17 $(18.9 \%)$ were hypertensive. Lilungulu et al ${ }^{7}$ also reported $18 \%$ hypertensive disorders with short interpregnancy interval, which is in compliance with that of our study results. 
Mean body mass index (BMI) of our study cases was noted to be $22.31 \pm 2.07 \mathrm{Kg} / \mathrm{m}^{2}$ (with minimum BMI was $19.2 \mathrm{~kg} / \mathrm{m}^{2}$ while maximum BMI was $31.3 \mathrm{~kg} / \mathrm{m}^{2}$ ). Al - Jasmi Fatima et al ${ }^{16}$ reported similar results from UAE.

Mean gestational age of our study cases was noted to be $24.02 \pm 8.31$ weeks (with minimum gestational age was 11 weeks while maximum gestational age was 34 weeks). Mean $\mathrm{Hb}$ level was noted to $10.67 \pm 0.893 \mathrm{~g} / \mathrm{dl}$ (with minimum $\mathrm{Hb}$ level was $9.6 \mathrm{~g} / \mathrm{dl}$ while maximum $\mathrm{Hb}$ level was $12.5 \mathrm{~g} / \mathrm{dl}$ ). Al - Jasmi Fatima et al ${ }^{16}$ from UAE reported $10.8 \mathrm{~g} / \mathrm{dl}$ ranging from 10.1 to $11.8 \mathrm{~g} / \mathrm{dl}$. These findings are similar to that of our study results. Anemia was noted in $74(82.2 \%)$ our study cases and only $23(25.6 \%)$ of our study cases were taking iron supplements (Treatment). Lilungulu et al ${ }^{7}$ reported anemia in $94 \%$ pregnant ladies with short interpregnancy interval. These findings are similar to that of our study results.

\section{Conclusion;}

Short interpregnancy interval less than 6 months is related with adverse pregnancy outcomes. Very high frequency of anemia was noted in our study cases having interpregnancy interval less than 6 months. Anemia was significantly associated with residential status, hypertension and iron supplementation. Birth spacing is an issue which women should have some control over. Educational interventions, including birth control, should be applied during prenatal visits and following delivery.

\section{References}

1. Salhan S, Tripathi V, Singh R, Gaikwad HS. Evaluation of hematological parameters in partial exchange and packed cell transfusion in treatment of severe anemia in pregnancy. Anemia. 2012;2012:608658. doi: $10.1155 / 2012 / 608658$.

2. Khalafallah AA, Dennis AE. Iron deficiency anaemia in pregnancy and postpartum: pathophysiology and effect of oral versus intravenous iron therapy. J Pregnancy. 2012;2012:630519. doi: 10.1155/2012/630519

3. Balarajan Y, Ramakrishnan U, Ozaltin E, Shankar AH, Subramanian SV. Anaemia in low-income and middle-income countries. Lancet. 2011 Dec 17;378(9809):2123-35.

4. Raza N, Sarwar I, Munazza B, Ayub M, Suleman M. Assessment of iron deficiency in pregnant women by determining iron status. J Ayub Med Coll Abbottabad. 2011 Apr-Jun;23(2):36-40.

5. Elzahrani SS. Prevalence of iron deficiency anemia among pregnant women attending antenatal clinics at Al-Hada Hospital. Canadian J Med. 2012;3(1):10-4.

6. Shachar BZ, Lyell DJ. Interpregnancy interval and obstetrical complications. Obstet Gynecol Surv2012;67:584-96.

7. Lilungulu A, Matovelo D, Kihunrwa A, Gumodoka B. Spectrum of maternal and perinatal outcomes among parturient women with preceding short inter-pregnancy interval at Bugando Medical Centre, Tanzania. Matern Health Neonatol Perinatol. 2015;1(1).doi:10.1186/s40748-014-0002-1

8. Hamid A, Gaafar H. Adverse effects of interpregnancy interval on maternal health among pregnant women attending delivery. Med J Cairo Univ.2011;79(2):31-41.

9. Yohannes S, Wondafrash M, Abera M, Girma E. Duration and determinants of birth interval among women of child bearing age in Southern Ethiopia. BMC Pregnancy Childbirth. 2011;11:38. doi: 10.1186/1471-2393-11-38.

10. Howard EJ, Harville E, Kissinger P, Xiong X. The association between short interpregnancy interval and preterm birth in Louisiana: A comparison of methods. Matern Child Health J. 2013;17(5):933-9.

11. Shipp TD, Zelop CM, Repke JT, Cohen A, Lieberman E: Interdelivery interval and risk of symptomatic uterine rupture. Obstet Gynecol 2001;97(2):175-7.

12. Begna Z, Assegid S, Kassahun W, Gerbaba M. Determinants of inter birth interval among married women living in rural pastoral communities of Southern Ethiopia: a case control study. BMC Pregnancy Childbirth. 2013;13:116.doi: 10.1186/1471-2393-13-116.

13. Dadi AF. A systematic review and meta-analysis of the effect of short birth interval on infant mortality in Ethiopia. PLoS One. 2015;10(5):e0126759. doi: 10.1371/journal.pone.0126759.

14. Chen $\mathrm{I}^{1}$, Jhangri GS $\mathrm{S}^{2}$, Lacasse $\mathrm{M}^{3}$, Kumar $\mathrm{M}^{4}$, Chandra $\mathrm{S}^{3}$. Relationship Between Interpregnancy Interval and Adverse Perinatal and Neonatal Outcomes in Northern Alberta. J Obstet Gynaecol Can. 2015 Jul;37(7):598-605.

15. Knight AK, Smith AK. Epigenetic Biomarkers of Preterm Birth and Its Risk Factors. Genes (Basel). 2016 Apr 13;7(4). pii: E15. doi: 10.3390/genes7040015. 
16. Al-Jasmi F, Al-Mansoor F, Al-Sheiba A, Carter AO, Carter TP, Hossain MM. Effect of interpregnancy interval on risk of spontaneous preterm birth in Emirati Women, United Arab Emirates. Bull World Health Organ. 2002;80(11);871-5.

17. Hussaini $\mathrm{KS}^{1}$, Ritenour D, Coonrod DV. Interpregnancy intervals and the risk for infant mortality: a case control study of Arizona infants 2003-2007. Matern Child Health J. 2013 May;17(4):646-53. 